\title{
Sex-related change in BMI of 15- to 16- year-old Norwegian girls in cross-sectional studies in 2002 and 2017
}

\author{
Asborg A. Bjertnaes ${ }^{1,2^{*}}$ (D, Jacob H. Grundt ${ }^{3}$, Petur B. Juliusson ${ }^{4,5,6}$, Trond J. Markestad ${ }^{7}$, Tor A. Strand ${ }^{7}$ and \\ Mads N. Holten-Andersen ${ }^{1,2}$
}

\begin{abstract}
Background: The prevalence of overweight and obesity (OWOB) has stabilized in some countries, but a portion of children with high body mass index (BMI) may have become heavier. This study aimed to describe the distributions of BMI and the point prevalence of OWOB in Norwegian adolescents in 2002 and 2017.

Methods: A cross-sectional study involving 15- to 16-year-old adolescents in Oppland, Norway, was undertaken in 2002 and 2017. We calculated their BMI, BMI z-scores (BMIz), and the prevalence of OWOB.

Results: The mean BMI increased from 20.7 to $21.4(p<0.001)$ for girls but remained unchanged at 21.5 vs 21.4 $(p=0.80)$ for boys. The prevalence of OWOB increased from 9 to $14 \%$ among girls (difference $5,95 \% \mathrm{Cl}: 2,8)$ and from 17 to $20 \%$ among boys (difference $3,95 \% \mathrm{Cl}:-1,6 \%$ ). The BMI density plots revealed similar shapes at both time points for both sexes, but the distribution for girls shifted to the right from 2002 to 2017.
\end{abstract}

Conclusion: Contrary to previous knowledge, we found that the increase in OWOB presented a uniform shift in the entire BMI distribution for 15-16-year-old Norwegian girls and was not due to a larger shift in a specific subpopulation in the upper percentiles.

Keywords: Adolescent, Body mass index, Body mass index distribution, Obesity, Overweight, Sex differences

\section{Background}

The relationship between body mass index (BMI) in adolescence and subsequent health in adulthood is well established [1-3], and both overly low and overly high BMI values are of concern [4]. The prevalence of adolescent overweight and obesity (OWOB) has increased over the last decades [5], and studies have found that this change is primarily due to increasing BMI in subgroups in the upper percentiles of the BMI distribution [6].

Population changes in BMI distributions over time have been studied in many countries [7-9], including the US [10]. However, relatively few European studies have addressed this issue in adolescents, and even fewer are based on data from the last decade when the obesity

\footnotetext{
* Correspondence: Asborg.Aanstad.Bjertnaes@sykehuset-innlandet.no ${ }^{1}$ Department of Paediatric and Adolescent Medicine, Innlandet Hospital Trust, Anders Sandvigs gate 17, 2609 Lillehammer, Norway

${ }^{2}$ Department of Clinical Medicine, University of Oslo, Oslo, Norway Full list of author information is available at the end of the article
}

epidemic is said to have stabilized in some countries [11].

Adolescents with obesity have a high risk of becoming adults with obesity [12]. As both the biology of OWOB [13] and comorbidities due to central fat distribution differ by sex [14], sex-related trends in adolescent OWOB are important to elucidate for public health reasons.

In this study, we compared BMI distributions and the prevalence of OWOB in Norwegian adolescents in 10th grade (15-16 years of age) at 15-year intervals stratified by sex. Our aim was to explore whether an increasing mean BMI and prevalence of OWOB was due to increasing BMI within a subgroup of adolescents.

\section{Methods \\ Subjects}

This cross-sectional study was based on questionnaires answered by 10th grade students (15-16 years old) in high schools in the district of Oppland, Norway, in

(c) The Author(s). 2019 Open Access This article is distributed under the terms of the Creative Commons Attribution 4.0 International License (http://creativecommons.org/licenses/by/4.0/), which permits unrestricted use, distribution, and reproduction in any medium, provided you give appropriate credit to the original author(s) and the source, provide a link to the Creative Commons license, and indicate if changes were made. The Creative Commons Public Domain Dedication waiver (http://creativecommons.org/publicdomain/zero/1.0/) applies to the data made available in this article, unless otherwise stated. 


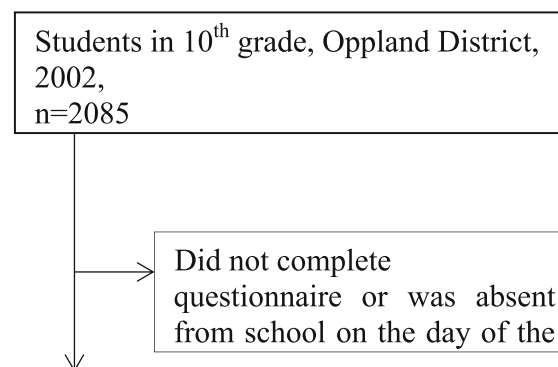

Completed questionnaire, $\mathrm{n}=1877(90 \%)$

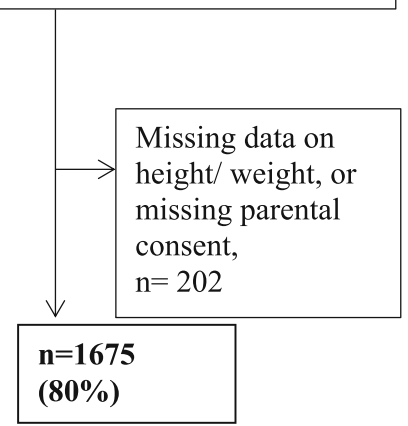

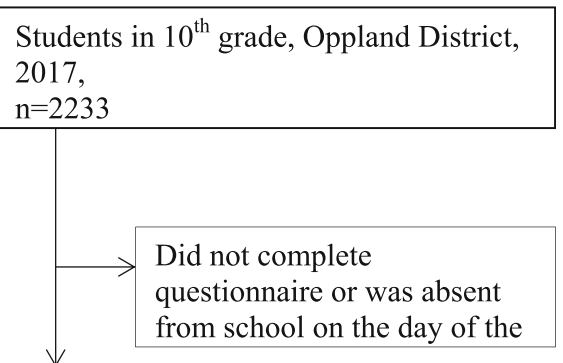

Completed questionnaire, $\mathrm{n}=1793(80.3 \%)$

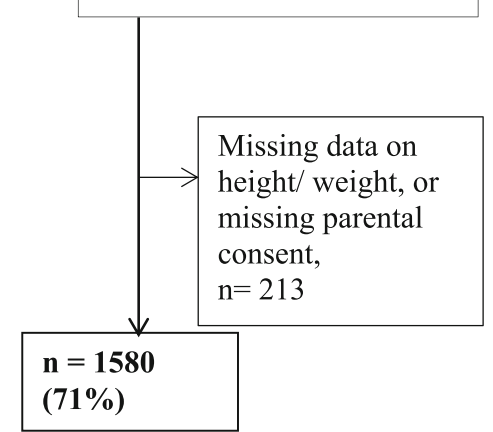

Fig. 1 Flowchart

April-June $2002(n=2085)$ and in April-May 2017 ( $n=$ 2233) (Fig. 1). Oppland is one of 18 counties in Norway and had a population of 183,000 in 2002 and 190,000 in 2017. The county is predominantly rural but has two major cities, each with populations of 25,000-30,000.

\section{Protocol and measures}

The Norwegian Institute of Public Health conducted the first survey in 2002 [15]. We conducted the second in 2017 in collaboration with the County Governor of Oppland, the supreme authority of all high schools in the county.

The survey was a paper-questionnaire in 2002 and a web-based questionnaire in 2017. Central questions including health, nutrition, activity, and perceived familial socioeconomic status from 2002, were repeated in 2017. Current weight and height measurements were selfreported in both surveys. The questionnaire used in 2017 was piloted among 842 students in 22 schools in 2015-2016. The 2002 questionnaire lacked the date of height and weight measurements. This date was needed to calculate $\mathrm{z}$-scores; thus, the date of questionnaire completion was used.

\section{Variables}

\section{Outcome variables}

Anthropometric measurements included self-reported weight (to the nearest $\mathrm{kg}$ ) and height (to the nearest $\mathrm{cm})$. Based on the self-reported anthropometric data, three outcome variables were calculated: BMI, BMI zscore (BMIz), and OWOB vs. under-weight and normalweight. For both 2002 and 2017-data, we based BMIz on updated Norwegian growth reference data [16] and defined OWOB according to the International Obesity Task Force (IOTF) [17].

\section{Background data (Table 1)}

Information on sex and age was available for all participants. The following background data were also collected.

Socio-demography of the family: We asked the adolescents if they lived with any siblings, how they classified their family economy compared to other families (poor, average, good, very good), if the parents lived together, and if the parents had full-time employment (full-time/ part-time/ unemployed or receiving social security services/ housewife/ student/ dead). We also included a question on frequency of teeth brushing ( $<$ every second day, every second day, once daily, >once daily), as higher family socioeconomic status is associated with greater odds of teeth brushing twice a day or more [18]. As a measure of rural living, place of residence was dichotomized into more or less than 20, 000 inhabitants. Smoking: We recorded smoking habits of the adolescents (never, used to but quit, sometimes, daily) and of their parents (yes/no). Mental health: We asked the adolescents if they had sought help for mental health problems in the past 12 months (yes/no). Activity: We recorded 
Table 1 Descriptive statistics of the background variables

\begin{tabular}{|c|c|c|c|c|c|c|}
\hline & 2002 & & & 2017 & & \\
\hline & $\bar{N}$ & $\%$ & OWOB $\%^{\mathrm{a}}$ & $\bar{N}$ & $\%$ & OWOB $\%^{a}$ \\
\hline Sex & 1675 & 823 & & 1580 & 814 & \\
\hline Girl & 823 & 49.1 & 9.0 & 814 & 51.5 & 14.0 \\
\hline Boy & 852 & 50.9 & 17.0 & 766 & 48.5 & 20.0 \\
\hline Age, years (mean) SD & 1675 & (15.9) 0.3 & & 1580 & (15.8) 0.4 & \\
\hline Sociodemography of the family & & & & & & \\
\hline Not living with siblings & 1631 & 17.0 & 14.4 & 1566 & 16.5 & 22.1 \\
\hline Poor family economy & 1656 & 3.5 & 24.1 & 1572 & 4.0 & 23.8 \\
\hline Parents not living together & 1664 & 27.1 & 13.1 & 1573 & 32.1 & 20.0 \\
\hline Father working full time & 1644 & 84.2 & 12.2 & 1560 & 84.5 & 16.4 \\
\hline Mother working full time & 1654 & 57.8 & 11.9 & 1569 & 70.2 & 16.0 \\
\hline Teeth brushing $\leq$ once daily & 1670 & 25.7 & 18.4 & 1573 & 24.1 & 24.0 \\
\hline Rural living & 1675 & 74.1 & 13.0 & 1580 & 72.3 & 18.7 \\
\hline Smoking & & & & & & \\
\hline Never smoked & 1671 & 62.4 & 13.2 & 1567 & 87.0 & 16.3 \\
\hline Parental smoking & 1675 & 35.8 & 14.0 & 1580 & 12.4 & 23.0 \\
\hline Mental health issues & & & & & & \\
\hline Sought help for mental health issues ${ }^{b}$ & 1573 & 5.2 & 14.6 & 1541 & 13.0 & 21.9 \\
\hline Activity & & & & & & \\
\hline Spare-time physical activity $<4$ times weekly ${ }^{c}$ & 1570 & 56.9 & 14.3 & 1576 & 55.9 & 19.3 \\
\hline Screen time $>2$ h/daily & 1666 & 57.6 & 14.8 & 1571 & 68.7 & 17.6 \\
\hline Participates in organized spare-time sports & 1659 & 43.5 & 9.3 & 1563 & 56.8 & 12.2 \\
\hline Walking or riding bike to school & 1665 & 35.6 & 11.6 & 1577 & 39.9 & 14.6 \\
\hline Student education & & & & & & \\
\hline Educational plans $>12$ years & 1659 & 46.6 & 11.7 & 1573 & 61.0 & 13.0 \\
\hline Best or second-best grades ${ }^{d}$ & 1555 & 55.3 & 11.2 & 1506 & 67.8 & 14.7 \\
\hline Positive opinion on education ${ }^{\mathrm{e}}$ & 1642 & 68.9 & 11.9 & 1565 & 78.9 & 16.2 \\
\hline Nutrition & & & & & & \\
\hline Daily breakfast & 1673 & 65.8 & 13.9 & 1576 & 62.9 & 15.3 \\
\hline Drinking sugar-containing soda $\geq$ daily & 1664 & 37.5 & 14.4 & 1561 & 13.4 & 16.3 \\
\hline Eating candy $\geq$ daily & 1660 & 17.7 & 9.9 & 1566 & 8.2 & 14.8 \\
\hline
\end{tabular}

${ }^{a} \%$ overweight and obesity (OWOB) within the given category

bduring the last 12 months

cactivity generating sweating or heavy breathing

$\mathrm{d}_{\text {in }} \geq 1$ of 4 subjects: Norwegian writing, mathematics, social science, English

eAnswered yes to $\geq 1$ of the questions "my education is interesting and I learn a lot", "good grades are important to me", and "my parents find

education important"

how frequently the adolescents participated in sparetime activities that generated heavy breathing or sweating (never, once per week, 2-3 times per week, 4-6 times per week, daily), how long they watched a screen (phone, computer, TV, tablet) daily during out-of-school hours $(<1 \mathrm{~h}, 1-2 \mathrm{~h}, 3-5 \mathrm{~h},>5 \mathrm{~h})$, if they attended organized spare-time sport activities (yes/no) and if they rode a bike or walked to school (yes/no).

We asked the adolescents to describe student education by three proxies: educational plans (planning for an education for 9 years, 11 years, 12 years, college or university degree), achievement of good grades (best or second-best grade in $\geq 1$ of the following subjects: Norwegian writing, mathematics, English, social science), and whether they had a positive opinion on education (answered agree/partly agree to $\geq$ one of the three questions "my education is interesting, and I learn a lot", "good grades are important to me", and "my parents find education important"). The adolescents also answered questions regarding nutrition by reporting how often 
they ate breakfast (seldom/never, 1-2 times per week, 3-4 times per week, 5-6 times per week, daily), drank sugar-sweetened soda (seldom/never, 1-6 glasses a week, 1 glass daily, 2-3 glasses daily, $\geq 4$ glasses daily) and how often they consumed candy (seldom/never, 1-3 times monthly, 1-3 times weekly, 4-6 times weekly, 1-2 times daily, $\geq 3$ times daily).

\section{Statistical analyses}

We calculated percentages, means and standard deviations for all included variables. The following background variables were dichotomized in the descriptive analysis (Table 1): Family economy into poor vs other, parental employment into full-time employment vs other, teeth brushing into $\leq$ once daily vs other, smoking habits into never vs other, spare-time physical activity $\geq 4$ times per week vs other, daily screen time $>2 \mathrm{~h}$ daily vs other, educational plans $>12$ years vs other, good grades into best or secondbest grade in $\geq 1$ of 4 subjects: Norwegian writing, mathematics, social science or English vs other, drinking sugarcontaining soda $\geq$ daily vs other and consumption of candy $\geq$ daily vs other.

We calculated mean differences by using student's ttests, and risk differences by the cohort study command in STATA.

Data were analyzed using STATA 15.0 software (STATA, College Station, TX, United States: StataCorp, 2017). The $95 \%$ CI of the difference in various percentiles between the two time points was calculated using bootstrap resampling with 1000 replicates. The distributions were created with Epanechnikov kernel density plots in R Version 3.4.2. Vienna, Austria: R Foundation for Statistical Computing, 2017, www.R-project.org).

\section{Results}

The mean age was 15.9 years (SD 0.3) in $2002(n=1675)$ and 15.8 years (SD 0.4) in $2017(n=1580)$. The proportions of boys were $50.9 \%$ in 2002 and $48.5 \%$ in 2017 (Table 1).

The 2017 cohort differed from the 2002 cohort in that more mothers worked full time, and that fewer parents smoked cigarettes. Further, fewer adolescents smoked and brushed their teeth $\leq$ once daily, but a larger portion sought help for mental health problems in 2017. More adolescents had screen time $>2 \mathrm{~h}$ daily, but more also participated in organized spare-time sports in 2017. There were more adolescents with a positive attitude towards higher education, and more adolescents achieved better grades and had plans for education beyond 12 years in 2017. Fewer adolescents consumed candy and sugar-containing soda daily in 2017 (Table 1).

The prevalence of OWOB increased by most background variables, including the sociodemographic variables, when comparing 2002 and 2017. (Table 1).

For girls, the mean BMI increased from 20.7 to 21.4 (mean difference 0.70, 95\% CI: $0.40,0.99, p<0.001$ ), while the mean BMI, at 21.5-21.4, was stable among boys $(p=0.80$, Table 2$)$.

The prevalence of OWOB increased from 9 to $14 \%$ among girls (difference 5 percentage points\%, $95 \mathrm{CI}$ : 2, 8) and from 17 to $20 \%$ among boys (difference 3 percentage point, 95\% CI: - 1, 6) (Table 3).

The shapes of the BMI density plots for both boys and girls were similar in 2002 and 2017 (Fig. 2). The mean BMIz increased significantly from -0.07 to 0.22 (mean difference $0.29,95 \%$ CI: $0.18,0.39$ ) among girls, while the numbers were stable at 0.19 (mean difference 0.00 , $95 \%$ CI $(-0.10,0.10)$ among boys. For girls, a persistent mean difference in BMIz between 0.21 and 0.35 was found across all percentiles (5th -95th). For boys, mean differences per percentile ranged between -0.06 and 0.09 (Table 4).

\section{Discussion}

The mean BMI and the prevalence of OWOB increased among Norwegian adolescent girls from 2002 to 2017. This change was due to an increase throughout the BMI distribution and is opposed to both our hypothesis and some previous findings $[8,9,19]$. No such change was seen for boys.

We found that the percentage of OWOB increased from 2002 to 2017 for almost all background variables, including the sociodemographic indicators. This finding is also supported by other studies [20] and it could be speculated that behavior has changed across socio-

Table 2 Mean anthropometric measurements of the participants, mean difference

\begin{tabular}{llllllll}
\hline & Girls & & Mean difference, 95\% Cl & $p$-value & Boys & & Mean difference, 95\% Cl \\
& 2002 & 2017 & & & 2002 & 2017 & \\
\hline Height, $\mathrm{cm}$ & 166.4 & 166.7 & & & 176.4 & 177.5 & \\
Weight, $\mathrm{kg}$ & 57.5 & 59.7 & & & 67.0 & 67.7 & \\
BMI $^{\mathrm{a}}$ & 20.7 & 21.4 & $0.7(0.37,0.95)$ & $<0.001$ & 21.5 & 21.4 & $-0.04(-0.35,0.27)$ \\
BMlz $^{\mathrm{b}}$ & -0.07 & 0.22 & $0.29(0.18,0.39)$ & $<0.001$ & 0.19 & 0.19 & $0.00(-0.10,0.10)$ \\
\hline
\end{tabular}

${ }^{\mathrm{a} B o d y}$ Mass Index (BMI)

${ }^{\mathrm{b}} \mathrm{BMI}$ z- score (BMIz) 
Table 3 Anthropometric measurements of the participants, risk difference

\begin{tabular}{lccccccrr}
\hline & Girls & & Risk Difference, 95\% Cl & $p$-value & Boys & & Risk difference, $95 \% \mathrm{Cl}$ & $p$-value \\
& 2002 & 2017 & & & 2002 & 2017 & \\
\hline OWOB $^{\text {a }} \%$ & 9 & 14 & $5(2,8)$ & 0.002 & 17 & 20 & $3(-1,6)$ & 0.18 \\
OB $^{\text {b } \%}$ & 1.8 & 2.5 & $0.7(-0.7,2)$ & 0.35 & 2.5 & 2.7 & $0.2(-1,2)$ & 0.73 \\
\hline
\end{tabular}

${ }^{\mathrm{a} O W O B}=$ overweight and obesity, age and sex-adjusted $\mathrm{BMI}>25$

${ }^{\mathrm{b}} \mathrm{OB}=$ obesity, age- and sex-adjusted $\mathrm{BMI}>30$

demographic levels towards a lifestyle favoring weight gain [21].

Public health promotion strategies and health-related habits are comparable between Norway and other European countries in many aspects. All children pay visits to the school nurse at 6,8 and 13 years of age with additional visits for vaccines. The diet in Norway is generally varied [22] and adherence to nutritional guidelines among adolescents resemble that of other European countries [23]. Finally, the percentage of Norwegian adolescents meeting recommendations for daily physical activity corresponds to results from other European studies on adolescents [24] [25]. Still, the prevalence of OWOB is increasing among both Norwegian adolescents and adults [22], as in many other European countries [26].

Our finding of increased OWOB prevalence in girls is supported by a nationwide Norwegian report carried out during the same period [24]. There is a possibility that a sex-related increase in BMI appeared among boys before our study; mean weights for boys entering the military muster at age 17 increased between 1995 and 2008 and seemed to stabilize and decrease thereafter [27]. A regional study also revealed a higher BMI and an increasing prevalence of overweight and higher BMI values above the upper percentiles among adolescent Norwegian boys between 1966 and 1969 and 1995-1997 [28]. International, long-term studies of adolescents have shown mixed results; the mean BMI increased more among European girls than European boys between 1975 and 2016 [29], whereas global trends of OWOB between 1980 and 2013 displayed only small sex-related differences [30]. However, national and international trends in adolescent BMI and OWOB are difficult to compare due to low numbers of studies and differences in methodologies and results. This point is illustrated by the latter two studies where different growth-curves are
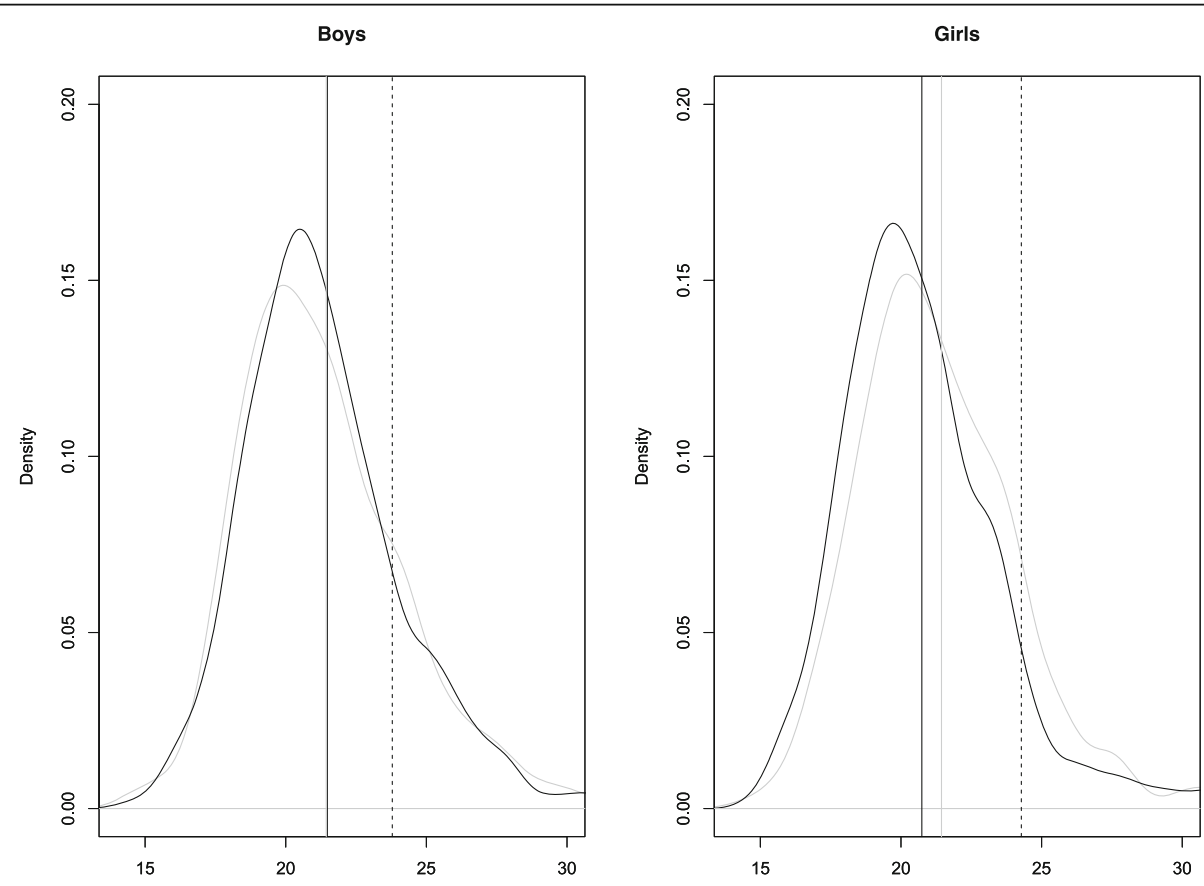

Fig. 2 BMI distribution of boys and girls. BMI distribution of boys and girls. (solid, vertikal black line) mean BMI (2002), (solid, vertical grey line) mean BMI (2017) 
Table 4 Mean differences (change in BMIz from 2002 to 2017 by percentile)

\begin{tabular}{cll}
\hline & Difference & $95 \% \mathrm{Cl}$ \\
\hline Girls & & \\
Percentile & & \\
5 & 0.21 & $(0.02,0.44)$ \\
10 & 0.31 & $(0.12,0.51)$ \\
25 & 0.33 & $(0.19,0.47)$ \\
50 & 0.29 & $(0.15,0.43)$ \\
75 & 0.35 & $(0.19,0.51)$ \\
90 & 0.30 & $(0.10,0.51)$ \\
95 & 0.22 & $(0.15,0.58)$ \\
Boys & & \\
Percentile & & $(-0.14,0.32)$ \\
5 & 0.09 & $(-0.22,0.11)$ \\
10 & -0.06 & $(-0.20,0.09)$ \\
25 & -0.05 & $(-0.14,0.09)$ \\
50 & -0.03 & $(-0.08,0.21)$ \\
75 & 0.06 & $(-0.18,0.17)$ \\
90 & 0.00 & $(-0.11,0.29)$ \\
95 & 0.09 & \\
\hline & &
\end{tabular}

used, resulting in different cut-points for overweight and obesity.

The average BMIs for girls in our study (20.7 and 21.4) are in the normal-weight range for both timepoints. Nevertheless, the increase in mean BMI is of clinical value, as changes in the mean value of a trait of a disease have established consequences for the frequency of illness [31]. Further, this will have consequences for the future prevalence of OWOB. Another important point is that the entire BMI-distribution for girls has shifted upwards on the BMI-scale from 2002 to 2017. This is underlined by the equal average increases in BMIz across percentiles for girls. This finding is concerning since girls, due to biological differences, gain increased fat mass compared to boys during adolescence [32].

For adolescent girls, our finding of an increased BMI throughout the total distribution may reveal a sexspecific obesogenic effect at the population level, and earlier studies have shown sex-related differences in weight gain due to both biological, behavioral and traumatic experiences [13,33-35]. Due to the limitations of the cross-sectional design and the lack of other body measurements and biological tests, we were not able to explore changes in important risk factors that could explain the shift in OWOB and BMI scores.

Nevertheless, some perspectives regarding the increased BMI among girls seem relevant to consider. First, the adolescents in this study were exposed to the obesity epidemic both pre-, peri- and postnatally and were born prior to (1986) and at the height (2001) of a period of increasing birthweights in Norway [36]. A higher birthweight is correlated with an increased risk for later overweight [37, 38], although not with central adiposity or fat mass per se $[39,40]$. The crossing of percentiles during the period from birth to adiposity rebound at 5-6 years of age has been seen as a critical period for later obesity, but might reflect increased growth in children that are already heavier instead [41]. Girls with higher BMI also tend to have earlier menarche, but the directionality of this relationship remains unclear [42]. In sum, children with high birthweight are vulnerable to subsequent higher BMI, but no clear pathway from high birthweight through adiposity rebound in pre-school age, early menarche and subsequent OWOB has been established.

Second, the obesity epidemic is a rather recent phenomenon that began 3 to 4 decades ago. Disentangling of the possible biological, societal, and environmental contributors to the etiology of obesity is ongoing. An example is the relatively newly gained knowledge of sex-specific increases in BMI and a higher risk of overweight in relation to dioxin exposure [43]. The main human sources of dioxins are foods, including meat, fatty fish, and dairy products, but dioxins are also concentrated in breast milk $[44,45]$. We do not have a detailed record of food-intake, and therefore no measure of dioxin exposure in our study. Still, $90 \%$ of the adolescent cohort from 2017 had been breastfed, [46] and exclusive breastfeeding in Norway increased between 1998 and 2006 [47]. The possibility of breastfeeding as a mediator of adolescent OWOB contradicts the traditional view of breastfeeding as a protective factor from later overweight [48].

A strength of this study was that we explored the entire BMI distribution. This provides more extensive information than only BMI means or OWOB percentages. We used BMI, as this is currently the recommended screening test for obesity. We are not aware of any recent studies exploring secular change in BMI distributions in adolescents in other populations.

A notable weakness of our study was that height and weight were self-reported. We assume, however, that self-reporting may have reduced the number of refusals. A meta-analysis on self-reported BMI revealed an underestimation of the prevalence of overweight and obesity among girls and older children [49]. In addition, a Norwegian study found that adolescent girls significantly underestimated their BMI [50], yet with a high degree of agreement between self-reported and measured anthropometrics measured by intraclass correlation (intra-class coefficient for BMI was 0.87 in girls). Online registration of self-reported height and weight has 
also been found to have high validity when compared to clinical examination [51]. This may imply a risk that our results underestimate the real BMI levels especially in girls, but likely so in both populations.

Another weakness is the lack of other metrics to explore overweight and obesity, i.e., waist circumference or percentage of body fat. BMI tends not to reflect percentage of body fat accurately [32], and especially among girls, an increase in waist circumference that is not explained by increase in BMI has been found [52].

Our study also lacks a measure of pubertal status. Females gain relatively more fat mass than boys during puberty and on average start puberty 2 years prior to boys. As the mean age of menarche in Norway has been stable at 13.2 years for the last 70 years [53] most girls in our study at both time points will have reached puberty. It is unlikely that puberty could explain the change in BMI for girls from 2002 compared to 2017.

The 2002 questionnaire lacked a date for when height and weight were measured, this may have led to modestly less precise calculations of BMIz. As both datacollections were conducted during the same months of the year, we again consider the datasets comparable.

A selection bias caused by a lower response rate among a larger group in the upper percentiles in 2017 cannot be completely ruled out. However, we have no specific indications of differences amongst the two groups of non-responders, and response rates of $80 \%$ (2002) and 70\% (2017) are comparable to earlier observational studies on childhood OWOB [54].

We found sex-related trends in BMI and OWOB among Norwegian 15- to 16-year-olds. Girls had an increasing prevalence of OWOB and an increased mean BMI over the last 15 years represented by a uniform right shift in the entire BMI distribution. Thus, a shift of the entire BMI distribution in girls is explaining the increased prevalence of OWOB. Using OWOB to describe how a population is affected by an obesogenic environment accordingly has inherent limitations as the number of individuals above this cutoff vastly underestimates the number affected. Although the Norwegian rates of OWOB for children and adolescents are low compared to those in other European countries [26], we know that increasing BMI in late adolescence increases the risk of death from coronary heart disease in adulthood [1]. As cardiovascular disease is a common cause of death, especially in women, the impact of our observed trend on future health may be significant.

\section{Conclusion}

We found that the increase in OWOB among 15-16year old Norwegian girls presented a uniform shift in the entire BMI distribution, and was not due to a larger shift in a specific subpopulation in the upper percentiles. This finding may have significant implications on future health in Norwegian women.

\section{Abbreviations \\ BMI: Body Mass Index; BMIz: BMI z-score; OWOB: Overweight or obesity}

\begin{abstract}
Acknowledgements
The assistance provided by Stian Hauge (County Governor of Oppland) in the collection of data was greatly appreciated. We also want to thank our nurses/research assistants, Anne Berit Klakegg Sundby, Ragnhild Gunstad, and Line Hovstein, who were present in each school class to answer questions and resolve technical problems during the 2017 data-collection.
\end{abstract}

\section{Authors' contributions}

$A A B$ contributed to the conception and design of the study, analyzed and interpreted the data, drafted and completed the manuscript. JHG contributed to the acquisition of data and revised the manuscript. PBJ revised the manuscript. TJM revised the manuscript. TAS contributed to the conception and design of the study, analysis and interpretation of data and drafting and completing the manuscript. MNHA contributed to the conception and design of the study, contributed to the collection of data and drafted and completed the manuscript. All authors read and approved the final manuscript.

\section{Funding}

This study was supported by unrestricted grants from the Innlandet Hospital Trust. The funding source did not play any role in the design and implementation of the study; collection, management, analysis or interpretation of the data; and preparation, review or approval of the manuscript.

\section{Availability of data and materials}

The part of the data collected in 2002 that support the findings of this study are available from the Norwegian Public Health Institute, but restrictions apply to availability of these data, which were used under the license for the current study, and so are not publicly available. Data collected in 2017 are however available from the authors upon reasonable request, and data collected in 2002 are available with permission of the Norwegian Public Health Institute.

\section{Ethics approval and consent to participate}

Written consent by parents for students who were younger than 16 years and by students who were older than 16 years was obtained on both occasions. The Regional Committee for Medical Research Ethics; Region South East, (University of Oslo), approved the study in both 2002 and 2017 (2017 project number: 2016/1755).

\section{Consent for publication}

Not applicable.

\section{Competing interests}

The authors declare that they have no competing interest.

\section{Author details}

'Department of Paediatric and Adolescent Medicine, Innlandet Hospital Trust, Anders Sandvigs gate 17, 2609 Lillehammer, Norway. ${ }^{2}$ Department of Clinical Medicine, University of Oslo, Oslo, Norway. ${ }^{3}$ Department of Paediatrics, Oslo University Hospital, Oslo, Norway. ${ }^{4}$ Department of Health Registries, Norwegian Institute of Public Health, Oslo, Norway. ${ }^{5}$ Department of Clinical Science, University of Bergen, Bergen, Norway. ${ }^{6}$ Department of Paediatrics, Haukeland University Hospital, Bergen, Norway. ${ }^{7}$ Department of Research, Innlandet Hospital Trust, Brumunddal, Norway.

Received: 24 May 2019 Accepted: 16 October 2019

Published online: 12 November 2019

References

1. Twig G, Yaniv G, Levine H, Leiba A, Goldberger N, Derazne E, et al. Bodymass index in 2.3 million adolescents and cardiovascular death in adulthood. N Engl J Med. 2016;374(25):2430-40.

2. Baker $\mathrm{JL}$, Olsen LW, Sorensen TI. Childhood body-mass index and the risk of coronary heart disease in adulthood. N Engl J Med. 2007;357(23):2329-37. 
3. Kvaavik E, Tell GS, Klepp K-I. Predictors and tracking of body mass index from adolescence into adulthood: follow-up of 18 to 20 years in the Oslo youth study. Archives of pediatrics \& adolescent medicine. 2003;157(12): 1212-8.

4. WHO. Adolescents: health risks and solutions 2018 http://www.who.int/en/ news-room/fact-sheets/detail/adolescents-health-risks-and-solutions

5. WHO. Overweight and obesity. 2018 https://www.who.int/news-room/factsheets/detail/obesity-and-overweight

6. Schonbeck $Y$, van Dommelen $P$, HiraSing RA, van Buuren S. Thinness in the era of obesity: trends in children and adolescents in the Netherlands since 1980. Eur J Pub Health. 2015;25(2):268-73.

7. Schaffrath Rosario A, Kurth BM, Stolzenberg $H$, Ellert U, Neuhauser $H$. Body mass index percentiles for children and adolescents in Germany based on a nationally representative sample (KiGGS 2003-2006). Eur J Clin Nutr. 2010:64:341.

8. Bjornelv S, Lydersen S, Mykletun A, Holmen TL. Changes in BMl-distribution from 1966-69 to 1995-97 in adolescents. The young-HUNT study, Norway. BMC Public Health. 2007;7:279.

9. Ekblom O, Oddsson K, Ekblom B. Prevalence and regional differences in overweight in 2001 and trends in BMI distribution in Swedish children from 1987 to 2001. Scandinavian journal of public health. 2004;32(4):257-63.

10. Ogden CL, Carroll MD, Kit BK, Flegal KM. Prevalence of obesity and trends in body mass index among US children and adolescents, 1999-2010. Jama. 2012;307(5):483-90.

11. Hales CM, Fryar CD, Carroll MD, Freedman DS, Ogden CL. Trends in Obesity and Severe Obesity Prevalence in US Youth and Adults by Sex and Age, 2007-2008 to 2015-2016. Jama. 2018.

12. Ward ZJ, Long MW, Resch SC, Giles CM, Cradock AL, Gortmaker SL. Simulation of growth trajectories of childhood obesity into adulthood. N Engl J Med. 2017;377(22):2145-53.

13. Shi H, Seeley RJ, Clegg DJ. Sexual differences in the control of energy homeostasis. Front Neuroendocrinol. 2009:30(3):396-404.

14. Li C, Engstrom G, Hedblad B, Calling S, Berglund G, Janzon L. Sex differences in the relationships between BMI, WHR and incidence of cardiovascular disease: a population-based cohort study. Int J Obes. 2006; 30(12):1775-81.

15. Norwegian Institute of Public Health, Soegaard A, Eide T. UNGHUBRO Protocol (2002) - English version 2013 https://www.fhi.no/globalassets/ dokumenterfiler/studier/helseundersokelsene/protokoll-unghubro-engelskversjon.pdf .

16. Juliusson PB, Roelants M, Nordal E, Furevik L, Eide GE, Moster D, et al. Growth references for 0-19 year-old Norwegian children for length/height, weight, body mass index and head circumference. Ann Hum Biol. 2013; 40(3):220-7.

17. Cole TJ, Lobstein T. Extended international (IOTF) body mass index cutoffs for thinness, overweight and obesity. Pediatric obesity. 2012;7(4): 284-94.

18. Levin KA, Currie C. Adolescent toothbrushing and the home environment: sociodemographic factors, family relationships and mealtime routines and disorganisation. Community Dent Oral Epidemiol. 2010;38(1):10-8.

19. Flegal KM, Troiano RP. Changes in the distribution of body mass index of adults and children in the US population. International journal of obesity and related metabolic disorders : journal of the International Association for the Study of Obesity. 2000;24(7):807-18.

20. Kautiainen S, Koivisto A-M, Koivusilta L, Lintonen T, Virtanen SM, Rimpelä A. Sociodemographic factors and a secular trend of adolescent overweight in Finland. Int J Pediatr Obes. 2009;4(4):360-70.

21. Chaput JP, Klingenberg L, Astrup A, Sjödin AM. Modern sedentary activities promote overconsumption of food in our current obesogenic environment. Obes Rev. 2011;12(5):e12-20.

22. Norwegian Institute of Public Health. Public Health Report: Health Status in Norway. Oslo, Norwegian Institute of Public Health. 2018.

23. Handeland K, Kjellevold M, Wik Markhus M, Eide Graff I, Frøyland L, Lie $\varnothing$, et al. A diet score assessing Norwegian Adolescents' adherence to dietary recommendations-development and test-retest reproducibility of the score. Nutrients. 2016;8(8):467.

24. Johannessen JS AS, Bratteteig M, Dalhaug EM, Andersen ID, Andersen OK, Kolle E, Ekelund U, Dalene KE. Nasjonalt overvåkingssystem for fysisk aktivitet og fysisk form: Norwegian School of Sports Sciences; 2019 https:// fhi.no/globalassets/bilder/rapporter-og-trykksaker/2019/ungkan3_rapport_ final_27.02.19.pdf
25. Guinhouya B, Samouda H, De Beaufort C. Level of physical activity among children and adolescents in Europe: a review of physical activity assessed objectively by accelerometry. Public Health. 2013;127(4):301-11.

26. WHO. Adolescent obesity and related behaviours: trends and inequalities in the WHO European Region, 2002-2014. http://www.euro.who.int/_data/ assets/pdf file/0019/339211/WHO_ObesityReport_2017_v3.pdf?ua=1 . 2017.

27. Statistics Norway, Kjellvik J. Vernepliktige opp i vekt 2011 https://www.ssb. no/helse/artikler-og-publikasjoner/vernepliktige-opp-i-vekt.

28. Bjornelv S, Lydersen S, Holmen J, Lund Nilsen TI, Holmen TL. Sex differences in time trends for overweight and obesity in adolescents: the young-HUNT study. Scandinavian journal of public health. 2009;37(8):881-9.

29. Abarca-Gómez L, Abdeen Z, Hamid Z, et al. Worldwide trends in body-mass index, underweight, overweight, and obesity from 1975 to 2016: a pooled analysis of 2416 population-based measurement studies in 128.9 million children, adolescents, and adults. Lancet. 2017;390(10113):2627-42

30. Ng M, Fleming T, Robinson M, Thomson B, Graetz N, Margono C, et al. Global, regional, and national prevalence of overweight and obesity in children and adults during 1980-2013: a systematic analysis for the global burden of disease study 2013. Lancet. 2014;384(9945):766-81.

31. Rose G. Sick individuals and sick populations. Int J Epidemiol. 1985:14(1):32-8.

32. Barbour-Tuck E, Erlandson MC, Johnson W, Muhajarine N, Foulds H, BaxterJones ADG. At what age do normal weight Canadian children become overweight adults? Differences according to sex and metric. Ann Hum Biol. 2018;45(6-8):478-85.

33. Labayen I, Ruiz JR, Huybrechts I, Ortega FB, Rodriguez G, Dehenauw S, et al. Sexual dimorphism in the early life programming of serum leptin levels in European adolescents: the HELENA study. J Clin Endocrinol Metab. 2011; 96(8):E1330-4.

34. Epel E, Lapidus R, McEwen B, Brownell KJP. Stress may add bite to appetite in women: a laboratory study of stress-induced cortisol and eating behavior Psychoneuroendocrinology. 2001;26(1):37-49.

35. Fuller-Thomson E, Sinclair DA, Brennenstuhl S. Carrying the pain of abuse: gender-specific findings on the relationship between childhood physical abuse and obesity in adulthood. Obesity Facts. 2013;6(4):325-36.

36. Grundt J, Nakling J, Eide GE, et al. Possible relation between maternal consumption of added sugar and sugar-sweetened beverages and birth weight-time trends in a population. BMC Public Health. 2012; 12(1):901.

37. Baird J, Fisher D, Lucas P, Kleijnen J, Roberts H, Law C. Being big or growing fast: systematic review of size and growth in infancy and later obesity. BMJ. 2005;331(7522):929.

38. Yu ZB, Han SP, Zhu GZ, Zhu C, Wang XJ, Cao XG, et al. Birth weight and subsequent risk of obesity: a systematic review and meta-analysis. Obes Rev. 2011;12(7):525-42.

39. Labayen I, Ruiz JR, Vicente-Rodríguez G, Turck D, Rodríguez G, Meirhaeghe A, et al. Early life programming of abdominal adiposity in adolescents: the HELENA study. Diabetes Care. 2009;32(11):2120-2.

40. Labayen I, Moreno LA, Blay MG, Blay VA, Mesana MI, Gonzalez-Gross M, et al. Early programming of body composition and fat distribution in adolescents. J Nutr. 2006;136(1):147-52.

41. Cole T. Children grow and horses race: is the adiposity rebound a critical period for later obesity? BMC Pediatr. 2004;4(1):6.

42. Prentice $P$, Viner RM. Pubertal timing and adult obesity and cardiometabolic risk in women and men: a systematic review and meta-analysis. Int J Obes. 2013;37(8):1036

43. Iszatt N, Stigum H, Govarts E, Murinova LP, Schoeters G, Trnovec T, et al. Perinatal exposure to dioxins and dioxin-like compounds and infant growth and body mass index at seven years: a pooled analysis of three European birth cohorts. Environ Int. 2016:94:399-407.

44. Norwegian Institute of Public Health O. Fakta om dioksiner og dioksinliknende PCB https://www.fhi.no/ml/miljo/miljogifter/fakta/dioksinerog-dl-pcb-faktaark/

45. Mead MN. Contaminants in human milk: weighing the risks against the benefits of breastfeeding. Environ Health Perspect. 2008;116(10):A427-34.

46. Bjertnæs AA, Grundt JH, Donkor HM, Juliusson PB, Wentzel-Larsen T, Vaktskjold A, et al. No significant associations between breastfeeding practices and overweight in 8-year-old children. Acta Paediatrica. 2019;0:1-6. https://doi.org/10.1111/apa.14937.

47. Paulsen MM Master's thesis, UIO. Trend over tid i kostholdet til 6 måneder gamle spedbarn i Norge 2010 https:/www.duo.uio.no/handle/10852/28601. 
48. Victora CG, Bahl R, Barros AJD, França GVA, Horton S, Krasevec J, et al. Breastfeeding in the 21st century: epidemiology, mechanisms, and lifelong effect. Lancet. 2016;387(10017):475-90.

49. He J, Cai Z, Fan X. How accurate is the prevalence of overweight and obesity in children and adolescents derived from self-reported data? A meta-analysis. Public Health Nutr. 2018;21(10):1865-73.

50. Gebremariam MK, Frost Andersen L, Bjelland M, Bergh IH, Totland TH, Ommundsen Y, et al. Are weight-related attitudes and behaviours associated with the accuracy of BMI derived from self-reported weight and height among 13-year-olds? Scandinavian journal of public health. 2015; 43(2):130-7.

51. Lassale C, Péneau S, Touvier M, Julia C, Galan P, Hercberg S, et al. Validity of web-based self-reported weight and height: results of the Nutrinet-Santé study. J Med Internet Res. 2013;15(8):e152.

52. Freedman DS, Kit BK, Ford ES. Are the recent secular increases in waist circumference among children and adolescents independent of changes in BMI? PLoS One. 2015;10(10):e0141056.

53. Bratke H, Bruserud IS, Brannsether B, Aßmus J, Bjerknes R, Roelants M, et al. Timing of menarche in Norwegian girls: associations with body mass index, waist circumference and skinfold thickness. BMC Pediatr. 2017;17(1):138.

54. Wijnhoven TM, van Raaij JM, Spinelli A, Starc G, Hassapidou M, Spiroski I, et al. WHO European childhood obesity surveillance initiative: body mass index and level of overweight among 6-9-year-old children from school year 2007/2008 to school year 2009/2010. BMC Public Health. 2014;14:806.

\section{Publisher's Note}

Springer Nature remains neutral with regard to jurisdictional claims in published maps and institutional affiliations.

Ready to submit your research? Choose BMC and benefit from:

- fast, convenient online submission

- thorough peer review by experienced researchers in your field

- rapid publication on acceptance

- support for research data, including large and complex data types

- gold Open Access which fosters wider collaboration and increased citations

- maximum visibility for your research: over $100 \mathrm{M}$ website views per year

At $\mathrm{BMC}$, research is always in progress.

Learn more biomedcentral.com/submissions 